\title{
Desenvolvimento pós-seminal de espécies de Poaceae (Poales) ${ }^{1}$
}

\author{
Adriana Tiemi Nakamura ${ }^{2,3}$ e Vera Lucia Scatena ${ }^{2}$
}

Recebido em 28/11/2007. Aceito em 10/06/2008

\begin{abstract}
RESUMO - (Desenvolvimento pós-seminal de espécies de Poaceae (Poales)). O presente estudo objetivou verificar a existência de um padrão do desenvolvimento pós-seminal em Poaceae. Para tanto, foram estudadas as seguintes espécies: Olyra humilis Nees (Bambusoideae); Axonopus aureus P. Beauv. e Paspalum polyphyllum Nees ex Trin. (Panicoideae); Chloris elata Nees e Eragrostis solida Desv. (Chloridoideae). Procurou-se também comparar as estruturas da plântula de Poaceae com as demais monocotiledôneas. As espécies estudadas são plantas perenes, rizomatosas, cespitosas e apresentam cariopses de tamanhos diferentes. Apresentam sementes albuminosas; embrião lateral, diferenciado, com raiz endógena (adventícia); cotilédone dividido em hiperfilo (escutelo), bainha reduzida e hipofilo (coleóptilo); coleorriza (raiz primária reduzida) e mesocótilo (eixo localizado entre o escutelo e coleóptilo). A presença de epiblasto (folha embrionária) foi observada em Olyra humilis, Chloris elata e Eragrostis solida. O desenvolvimento pós-seminal é semelhante nas espécies estudadas e forma um padrão em Poaceae. Primeiramente, observa-se a emissão da coleorriza, que cresce no sentido geotrópico positivo, seguida do coleóptilo e plúmula que crescem em sentido contrário, a partir do desenvolvimento do mesocótilo. As primeiras folhas são semelhantes às folhas definitivas (metafilos) das espécies, exceto em Olyra humilis, que são modificadas em catafilos e podem ser interpretadas como caráter basal em Bambusoideae. Raiz primária reduzida (coleorriza) e hipofilo modificado em coleóptilo são considerados caracteres derivados em Poaceae, quando comparados com as demais monocotiledôneas.
\end{abstract}

Palavras-chave: anatomia, Gramineae, morfologia, plântula, semente

\begin{abstract}
Post-seminal development of Poaceae species (Poales)). This work has aimed to verify the existence of a pattern of the post-seminal development in Poaceae. Thus, Olyra humilis Nees (Bambusoideae); Axonopus aureus P. Beauv. e Paspalum polyphyllum Nees ex Trin. (Panicoideae); Chloris elata Nees e Eragrostis solida Desv. (Chloridoideae) have been studied. Besides, it was compared the structures of Poaceae seedlings with those of other monocotyledons. All are perennial, rhizomatous, and cespitous species whose caryopses differ in size. They all present albuminous seeds, lateral and differentiated embryos, with endogenous embryonic (adventitious) root, cotyledons divided into hyperphyll (scutellum), reduced sheath and hypophyll (coleoptile); coleorhiza (reduced primary root); and mesocotyl (axis between the scutellum and the coleoptile). The presence of epiblasts (embryonic leaves) was noticed in Olyra humilis, Chloris elata and Eragrostis solida. Since the post-seminal developmental of all the studied species is similar, it represents a pattern in Poeaceae. The coleorhiza, which shows positive geotropism, grows first, followed by the coleoptile and the plumule, in the opposite direction, which form from the mesocotyl development. In all species, the first leaves are similar to the definitive ones (metaphyll) except Olyra humilis, where they are converted into a cataphyll - probably interpreted as a basal character in Bambusoideae. The reduced primary root (coleorhiza) and the hypophyll, which is modified into a coleoptile, are considered derived features in Poaceae, when compared with the other monocotyledons.
\end{abstract}

Key words: anatomy, Gramineae, morphology, seed, seedling

\section{Introdução}

Em monocotiledôneas, inclusive Poales, a morfologia do embrião, só pode ser comparada através do estudo do desenvolvimento pós-seminal (Eames 1974), visto que suas sementes, na maioria, apresentam embrião indiferenciado (Werker 1997; GPWG 2001).

Poaceae é um grupo peculiar de monocotiledôneas que apresenta embrião diferenciado na semente madura, ocupando posição lateral e periférica ao endosperma, caráter considerado sinapomórfico para a família (GPWG 2001). Caracteres morfológicos do embrião foram utilizados nos estudos filogenéticos de Poaceae realizados pelo GPWG (2001). Estudos realizados por Reeder (1957; 1962) com embrião de Poaceae, voltados à sistemática, utilizaram presença ou ausência de fenda no escutelo, presença ou ausência de epiblasto, vascularização e sobreposição ou encontro das margens da primeira folha plumular como caracteres importantes no agrupamento natural dos gêneros da família.

\footnotetext{
1 Parte da Tese de Doutorado da primeira Autora no Programa de Pós-Graduação em Ciências Biológicas, Biologia Vegetal, Universidade Estadual Paulista

2 Universidade Estadual Paulista, Instituto de Biociências, Departamento de Botânica, Av. 24-A 1515, Bela Vista, C. Postal 199, 13506-900 Rio Claro, SP, Brasil

3 Autor para correspondência: tieminak@yahoo.com.br
} 
Estudos com embriões de Poaceae apontaram que cada uma de suas estruturas apresenta homologia com o embrião das demais monocotiledôneas (Cocucci \& Astegiano 1978). Segundo os autores, a coleorriza, o coleóptilo e o epiblasto são homólogos à radícula, à lígula da folha cotiledonar (escutelo) e à bainha do cotilédone, respectivamente. Homologias entre escutelo e cotilédone, coleóptilo e primeira folha embrionária, coleorriza e radícula, epiblasto e colar foram utilizadas por Dahlgren et al. (1985) em Commeliniiflorae.

Utilizando características de plântulas de monocotiledôneas como ferramenta para a sistemática do grupo, Tillich $(1995 ; 2000)$ considerou várias homologias entre Poaceae e as demais monocotiledôneas. $\mathrm{O}$ autor afirmou que Poaceae não apresenta radícula e que a coleorriza é a região inferior do hipocótilo (colar). Tillich (2007) registrou ainda que epiblasto é uma excrescência da coleorriza e coleóptilo é uma bainha cotiledonar modificada (Tillich 2007).

Como Poaceae apresenta estrutura e nomenclatura seminal peculiar dentre as demais monocotiledôneas, o presente trabalho objetivou estudar a morfoanatomia da planta durante o desenvolvimento pós-seminal de Olyra humilis Nees (Bambusoideae-Olyreae), considerada no contexto deste trabalho como basal; Axonopus aureus P. Beauv. e Paspalum polyphyllum Nees ex Trin. (Panicoideae-Paniceae), intermediárias; Chloris elata Nees (Chloridoideae-Cynodonteae) e Eragrostis solida Desv. (Chloridoideae-Eragrostideae), derivadas (GPWG 2001). Com isso, procurou-se verificar se existe ou não um padrão do desenvolvimento pós-seminal para a família e comparar suas estruturas com as demais monocotiledôneas já estudadas.

\section{Material e métodos}

Exemplares das espécies estudadas foram coletados, herborizados e incluídos no herbário do Departamento de Botânica da Universidade Federal do Rio Grande do Sul (ICN) e no Herbário Rioclarense (HRCB), sob os números:

Bambusoideae - Olyreae: Olyra humilis Nees BRASIL. Rio Grande do Sul: Porto Alegre, 25/IX/2004, Longhi-Wagner 9258 (ICN).

Olyra humilis Nees - BRASIL. Rio Grande do Sul: Sapiranga, 25/IX/2004, Longhi-Wagner 9259 (ICN). Seus indivíduos ocorrem em áreas florestais, beira de mata e sub-bosque de capoeira úmida (Oliveira \& Longhi-Wagner 2001).

Panicoideae - Paniceae: Axonopus aureus P. Beauv. - BRASIL. São Paulo: Pratânia, 10/II/2005, Nakamura \& Campos s.n. (HRCB 41668).

Axonopus aureus P. Beauv. - BRASIL. São Paulo:
Pedregulho, 18/IV/2005, Nakamura \& Simão s.n. (HRCB 41661). Os representantes dessa espécie ocorrem em áreas campo limpo (Valls et al. 2001).

Paspalum polyphyllum Nees ex Trin. - BRASIL. Minas Gerais: Santana do Riacho, 11/V/2003, Coan et al. 08 (HRCB). Seus representantes ocorrem em campos altos, várzeas e áreas antropizadas (Oliveira \& Valls 2001).

Chloridoideae - Cynodonteae: Chloris elata Nees BRASIL. São Paulo: Franca, 14/XI/2005, Nakamura \& Simão s.n. (HRCB 45417). Espécie ruderal, ocorrendo nos campos altos e secos, além de serem comuns em beiras de estradas (Longhi-Wagner 2001).

Chloridoideae - Eragrostideae: Eragrostis solida Desv. - BRASIL. São Paulo: Pedregulho, 18/IV/2005, Nakamura \& Simão s.n. (HRCB 41667). A espécie ocorre em áreas de cerrado, campo graminoso ou arbustivo e raramente em locais alterados (Boechat et al. 2001).

\section{Descrição das espécies}

Olyra humilis (Bambusoideae) (Fig. 1-2) é perene, cespitosa, com colmo decumbente ou ereto, com ca. $1 \mathrm{~m}$ compr., que cresce a partir do rizoma horizontal (Fig. 2). As folhas se distribuem ao longo do colmo, alternas, com bainha alongada, do mesmo comprimento que a lâmina, com lígula membranosa de cerca de $0,8 \mathrm{~mm}$ compr. e pseudo-pecíolo com até $2 \mathrm{~mm}$ compr. A lâmina foliar é oval-lanceolada (Fig. 1) e glabra, com até $11 \times 3,2 \mathrm{~cm}$. Apresenta espiguetas distribuídas em panícula laxa de cerca de $15 \mathrm{~cm}$, com espiguetas femininas no ápice de cada cacho e espiguetas masculinas, em maior número, nas demais regiões da panícula.

Axonopus aureus (Panicoideae) (Fig. 3-4) é perene, cespitoso-ereta, forma touceira (Fig. 3) com até $70 \mathrm{~cm}$ alt., com colmo vertical que cresce a partir do rizoma (Fig. 4). As folhas são alternas, dispostas ao longo do colmo, com bainha de comprimento maior que a lâmina e tricomas curtos nas margens. A lígula é membranosociliada com cerca de $0,5 \mathrm{~mm}$ compr. A lâmina é plana, linear (Fig. 3), com até $15 \times 0,3 \mathrm{~cm}$. Apresenta inflorescência em cacho, com ráquis de cerca de $10 \mathrm{~cm}$, com tricomas dourados de até $2 \mathrm{~mm}$; espiguetas com flores hermafroditas distribuídas ao longo do seu eixo.

Paspalum polyphyllum (Panicoideae) (Fig. 5-6) é perene, cespitoso-decumbente (Fig. 5), com até $66 \mathrm{~cm}$ compr. O rizoma varia desde horizontal até vertical (Fig. 6). As folhas estão dispostas de maneira alterna ao longo do colmo. A bainha foliar é pilosa no ápice e seu comprimento é maior que a lâmina. A lígula é membranosa e mede até $1 \mathrm{~mm}$. A lâmina é plana, lanceolada, pilosa em ambas as faces, com até $11 \times 0,6 \mathrm{~cm}$. Apresenta 
inflorescência em cacho, com um a quatro ramos. A ráquis mede cerca de $5 \mathrm{~cm}$ e apresenta espiguetas com tricomas esbranquiçados e flores hermafroditas.

Chloris elata (Chloridoideae) (Fig. 7-8) é perene, cespitoso-ereta, forma touceiras de até $1,2 \mathrm{~m}$ compr. (Fig. 7), com colmos que saem do rizoma reduzido (Fig. 8). Apresentam folhas de prefoliação convoluta presentes na base e ao longo dos colmos. A bainha é glabra e apresenta metade do comprimento da lâmina. A lígula é membranoso-ciliada com cerca de $0,2 \mathrm{~mm}$. A lâmina foliar é glabra e linear-lanceolada (Fig. 7), com até $40 \times 0,9 \mathrm{~cm}$. Inflorescência do tipo panícula, com cerca de 15 ramos unilaterais pendentes, com espiguetas alvas, pilosas e flores hermafroditas.

Eragrostis solida (Chloridoideae) (Fig. 9-10) é perene, cespitoso-ereta, que forma touceira (Fig. 10) de até $83 \mathrm{~cm}$ alt. Apresenta colmo que se desenvolve a partir do rizoma (Fig. 9). A folha apresenta bainha glabra ou pilosa que alcança metade do comprimento da lâmina, lígula pilosa de $0,1 \mathrm{~mm}$ e lâmina foliar linear (Fig. 10), pilosa e com até $21 \times 0,4 \mathrm{~cm}$. A inflorescência é do tipo panícula, com cerca de $20 \mathrm{~cm}$, espiguetas de coloração arroxeada, com flores hermafroditas.

Para o estudo morfoanatômico do desenvolvimento pós-seminal, cariopses maduras foram individualizadas das inflorescências sem os verticilos protetores (pálea e lema). Foram semeadas em placas de petri, forradas com papel de filtro umedecido com água destilada. As placas foram colocadas em estufa encubadora a $30^{\circ} \mathrm{C} \pm 2{ }^{\circ} \mathrm{C}$, sob luz branca constante de lâmpadas fluorescentes de $15 \mathrm{~W}$.

O acompanhamento das fases de desenvolvimento pós-seminal foi feito por meio de observações diárias. No caso de Chloris elata, que apresenta crescimento muito rápido, as observações foram feitas de quatro em quatro horas, nas primeiras 24 horas, com encerramento após a expansão da segunda folha.

As plântulas nas diversas fases de desenvolvimento foram fixadas em FAA 50 e conservadas em álcool etílico a 70\% (Johansen 1940). Para o estudo morfológico, as diferentes fases do desenvolvimento das plântulas foram ilustradas a lápis preto por meio de desenhos produzidos sob estereomicroscópio com auxílio de câmara clara.

Para o estudo anatômico das diferentes fases de desenvolvimento pós-seminal foram confeccionadas lâminas permanentes, a partir de material desidratado em solução de álcool etílico e incluídas em metacrilato Leica, segundo o protocolo do fabricante. O material foi seccionado longitudinalmente, com cerca de $7 \mu \mathrm{m}$ espess. As secções foram coradas com ácido periódico $1 \%$, reagente de Schiff (PAS) e azul de toluidina $0,05 \%$ (Feder \& O'Brien 1968), e montadas em resina sintética.
As imagens foram obtidas por meio de capturador de imagens, acoplado ao fotomicroscópio Leica DMLB (programa Leica IM50).

\section{Resultados}

As cariopses das espécies estudadas apresentam tamanhos diferentes, sendo maiores em Olyra humilis (Bambusoideae) (Fig. 11), com cerca de $1 \mathrm{~cm}$ compr. e menores em Axonopus aureus (Fig. 12), Paspalum polyphyllum (Panicoideae), Chloris elata (Fig. 13) e Eragrostis solida (Fig. 27) (Chloridoideae) com cerca de $0,15 \mathrm{~cm}$ compr. Todas as espécies apresentam sementes albuminosas, com embrião lateral e diferenciado (Fig. 14-20). O endosperma constitui-se de células com amido que ocupam grande parte da semente (Fig. 14, 16-19), com uma camada de grãos de aleurona distribuída na região periférica da semente, como pode ser observado em Paspalum polyphyllum (Panicoideae) (Fig. 16 - cabeça de seta).

A proporção entre o tamanho do embrião e o volume do endosperma varia entre as espécies. O embrião pode ocupar quase metade da semente em Paspalum polyphyllum (Fig. 16), um terço em Axonopus aureus (Fig. 17) e Chloris elata (Fig. 18), um sexto em Eragrostis solida (Fig. 19) ou menos de um décimo da semente em Olyra humilis (Fig. 14).

$\mathrm{O}$ embrião das espécies estudadas apresenta escutelo, coleóptilo, plúmula, mesocótilo, raiz de origem endógena e coleorriza (Fig. 15-20). O epiblasto, excrescência lateral oposta ao escutelo, é observado em Olyra humilis (Bambusoideae), Eragrostis solida e Chloris elata (Chloridoideae) (Fig. 15, 18-20 - seta). As células que constituem o embrião são meristemáticas, e formam a protoderme, o meristema fundamental e o procâmbio (Fig. 21-23).

O cotilédone, em todas as espécies estudadas, é separado da coleorriza por uma fenda (Fig. 15-20*). É dividido em três regiões: hiperfilo ou haustro (escutelo), que é a parte superior do cotilédone; bainha, que é reduzida à região basal do coleóptilo; e hipofilo (coleóptilo), estrutura que protege a plúmula. A plúmula apresenta meristema apical caulinar envolvido pelos primórdios foliares (Fig. 15-17).

O mesocótilo é o eixo que se estende da região basal do coleóptilo até a inserção do nó cotiledonar (primeiro entrenó). A partir da região do nó cotiledonar, origina-se a raiz primeira raiz adventícia presente no embrião (Fig. 20) e também as demais raízes adventícias da plântula (Fig. 39-41). A coleorriza envolve a raiz endógena e é uma estrutura não vascularizada, preenchida pelo meristema fundamental e delimitada pela protoderme (Fig. 15-20). 


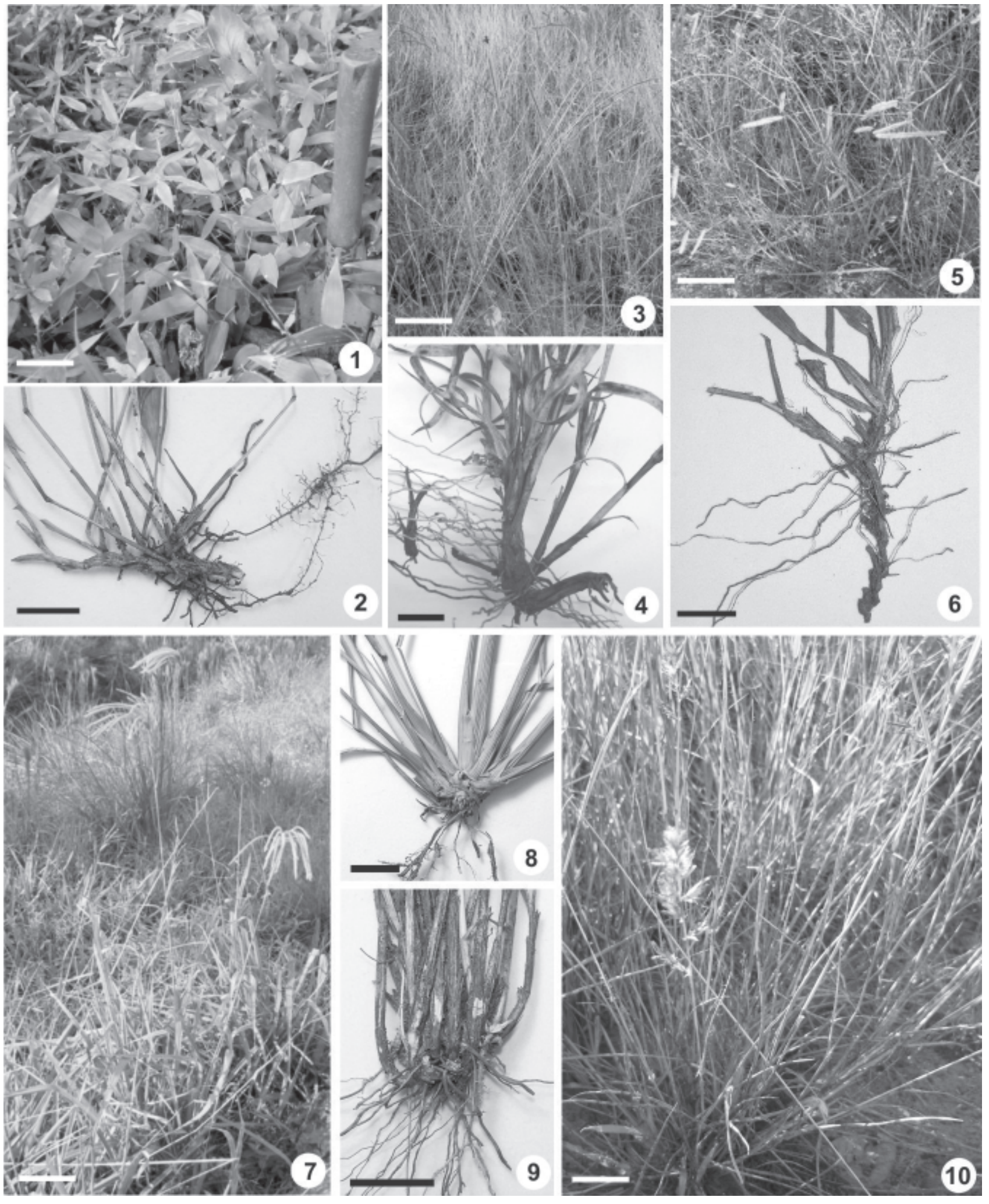

Figuras 1-10. Hábito e detalhe do rizoma de espécies de Poaceae. 1-2. Olyra humilis Nees (Bambusoideae-Olyreae). 3-4. Axonopus aureus P. Beauv. (Panicoideae-Paniceae). 5-6. Paspalum Paspalum polyphyllum Nees ex Trin. (Panicoideae-Paniceae). 7-8. Chloris elata Nees (Chloridoideae-Cynodonteae). 9-10. Eragrostis solida Desv. (Chloridoideae-Eragrostideae). Barras = 1,0 cm (7, 10); 1,5 cm (2, 4, 6, 8-9); $2,0 \mathrm{~cm}(1,5) ; 3,0 \mathrm{~cm} \mathrm{(3).}$ 

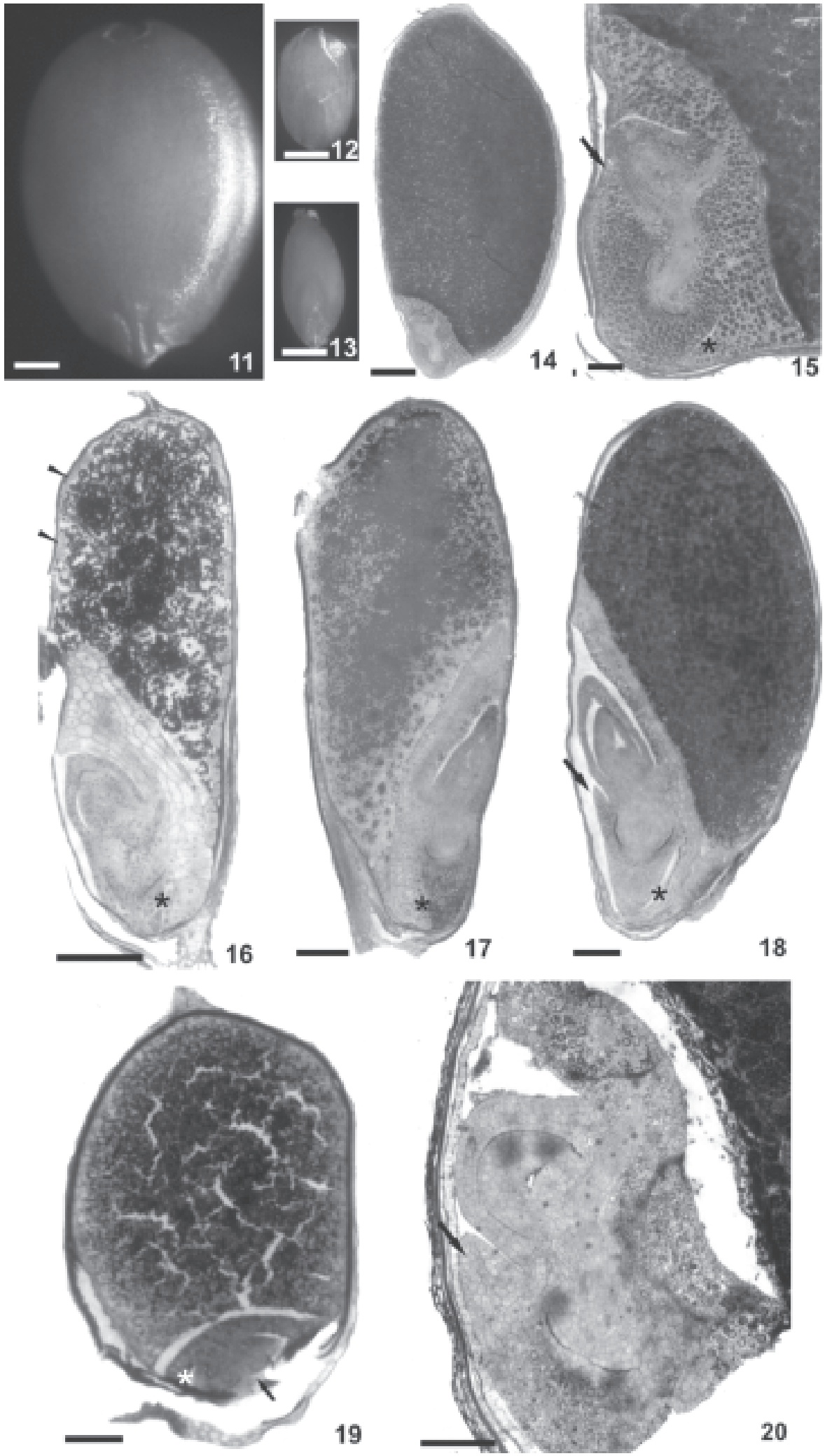

Figuras 11-20. Morfologia e fotomicrografias da cariopse de espécies de Poaceae em secção longitudinal. 11-13. Vista geral da cariopse de Olyra humilis Nees, Axonopus aureus P. Beauv. e Chloris elata Nees, respectivamente, comparando o tamanho das mesmas. 14. Cariopse de O. humilis. 15. Embrião de O. humilis. 16. Paspalum polyphyllum Nees ex Trin. - cabeça de seta indica camada de aleurona. 17. Cariopse de A. aureus. 18. Cariopse de C. elata. 19. Cariopse de Eragrostis solida Desv. 20. Detalhe do embrião de O. humilis. Seta: epiblasto; * - fenda do escutelo. Barras = $1000 \mu \mathrm{m}$ (11-14); $150 \mu \mathrm{m}$ (15-19); $100 \mu \mathrm{m}(20)$. 
Nas espécies estudadas, a embebição das cariopses se dá em torno de 20 horas. Observa-se que neste momento, a cariopse quase dobra o seu tamanho, como pode ser observado em Eragrostis solida (Fig. 28), quando comparado com a cariopse seca (Fig. 27). O processo germinativo é iniciado em até 24 horas, quando se observa a saída da coleorriza, que envolve a raiz endógena (Fig. 29). Entre as espécies estudadas, Chloris elata (Chloridoideae) apresenta geminação mais rápida, cerca de 16 horas após o início da embebição e Olyra humilis (Bambusoideae) (Fig. 35-36) apresenta germinação mais lenta, cerca de oito semanas.

$\mathrm{O}$ desenvolvimento da primeira raiz adventícia rompe a coleorriza após 24 horas do início da embebição. A coleorriza pode permanecer na plântula, indicando o pólo radicular (Fig. 31, 33-35, 39 - dupla cabeça de seta) e pode apresentar pêlos (Fig. 31, 33-34, 38-39 - dupla cabeça de seta). O epiblasto é de tamanho reduzido e melhor evidenciado sob estereomicroscópio (Fig. 31 seta) ou com auxílio de microscopia de luz, através das secções longitudinais da plântula (Fig. 24, 26 - seta). Durante o desenvolvimento pós-seminal o mesocótilo se alonga e observa-se a emergência do coleóptilo, no sentido oposto à coleorriza, com crescimento geotrópico negativo (Fig. 24-26, 30-32). No interior do coleóptilo, observa-se a plúmula (Fig. 24-26).

Após 48 horas do início da embebição observa-se maior crescimento da raiz adventícia, que apresenta pêlos, e também maior crescimento das folhas, que não estão totalmente expandidas (Fig. 34).

Com 96 horas do início da embebição observa-se o desenvolvimento das raízes adventícias e o desenvolvimento da segunda folha (Fig. 37, 39-40). As raízes adventícias crescem rapidamente e alcançam o comprimento da raiz do embrião em cinco ou seis dias (Fig. 41).

Depois de 120 horas do início da embebição, as plântulas já estão mais desenvolvidas e apresentam folhas planas, lineares, paralelinérveas, com bainha inconspícua devido aos entrenós curtos dos colmos. Olyra humilis (Bambusoideae) apresenta as duas primeiras folhas distintas das demais espécies, com a bainha mais desenvolvida que a lâmina foliar, e a primeira é um catafilo (Fig. 35-36).

Durante todo o período de observação a cariopse ficou aderida à plântula (Fig. 41), apesar do seu endosperma ter sido completamente absorvido com cerca de nove dias de desenvolvimento pós-seminal.

\section{Discussão}

A diferença no tamanho das sementes de Olyra humilis (Bambusoideae), que é maior do que as sementes de Axonopus aureus, Paspalum polyphyllum (Panicoideae), Chloris elata e Eragrostis solida (Chloridoideae), pode ser explicada porque Olyra humilis é a única espécie, dentre as estudadas, que habita regiões florestais (Oliveira \& Longhi-Wagner 2001). Segundo Roth (1987), em florestas tropicais, o aumento da densidade dos indivíduos e a diminuição da incidência de luz ao nível do solo podem levar ao aumento do peso, e conseqüentemente do tamanho das sementes, o que explica o maior tamanho das sementes de Olyra humilis em relação às espécies que ocorrem em cerrado e áreas antropizadas.

Espécies de monocotiledôneas apresentam sementes tipicamente albuminosas (Werker 1997), assim como também o são as de Poaceae em geral (GPWG 2001). A proporção entre endosperma e embrião é um caráter divergente (Reeder 1957). Segundo a classificação de sementes de Angiospermas de Martin (1946), Olyra humilis (Bambusoideae) e Eragrostis solida (Chloridoideae) apresentam sementes do tipo pequeno, pois o embrião ocupa menos de um quarto da semente enquanto que as de Axonopus aureus, Paspalum polyphyllum (Panicoideae) e Chloris elata (Chloridoideae) se encaixam no tipo um quarto, ocupando mais de um quarto e menos da metade da semente. Apesar da classificação de Martin (1946) agrupar as espécies estudadas em dois tipos de sementes, observou-se que as sementes de Olyra humilis (Bambusoideae) apresentam embrião muito menor do que o das demais espécies, com proporção do embrião em relação ao endosperma de 1:10. Em Leguminosas, Gunn (1981) observou que sementes de espécies consideradas ancestrais apresentam grande quantidade de endosperma em relação às espécies consideradas derivadas. No caso, a grande quantidade de endosperma das sementes de Olyra humilis também pode ser considerada caráter ancestral dentro de Poaceae, pois Bambusoideae é tida como ancestral em relação às subfamílias Panicoideae e Chloridoideae (GPWG 2001).

Alguns autores fizeram homologias das estruturas do embrião de Poaceae com as estruturas que compõem o embrião de outras monocotiledôneas e indicaram que o embrião de Poaceae apresenta as mesmas estruturas que o embrião das demais espécies de monocotiledôneas. Boyd (1931) afirmou que escutelo e epiblasto são partes do cotilédone e coleóptilo é a segunda folha plumular. Negbi \& Koller (1962) afirmaram que escutelo, epiblasto e coleóptilo são folhas embrionárias e que coleorriza é a raiz primária. Cocucci \& Astegiano (1978) afirmaram que o escutelo é a folha do embrião modificada pela função haustorial e que a coleorriza é homóloga à radícula. Além disso, esses últimos autores fizeram homologias dos embriões com folha adulta e com lema aristado de algumas espécies de Poaceae e afirmaram 

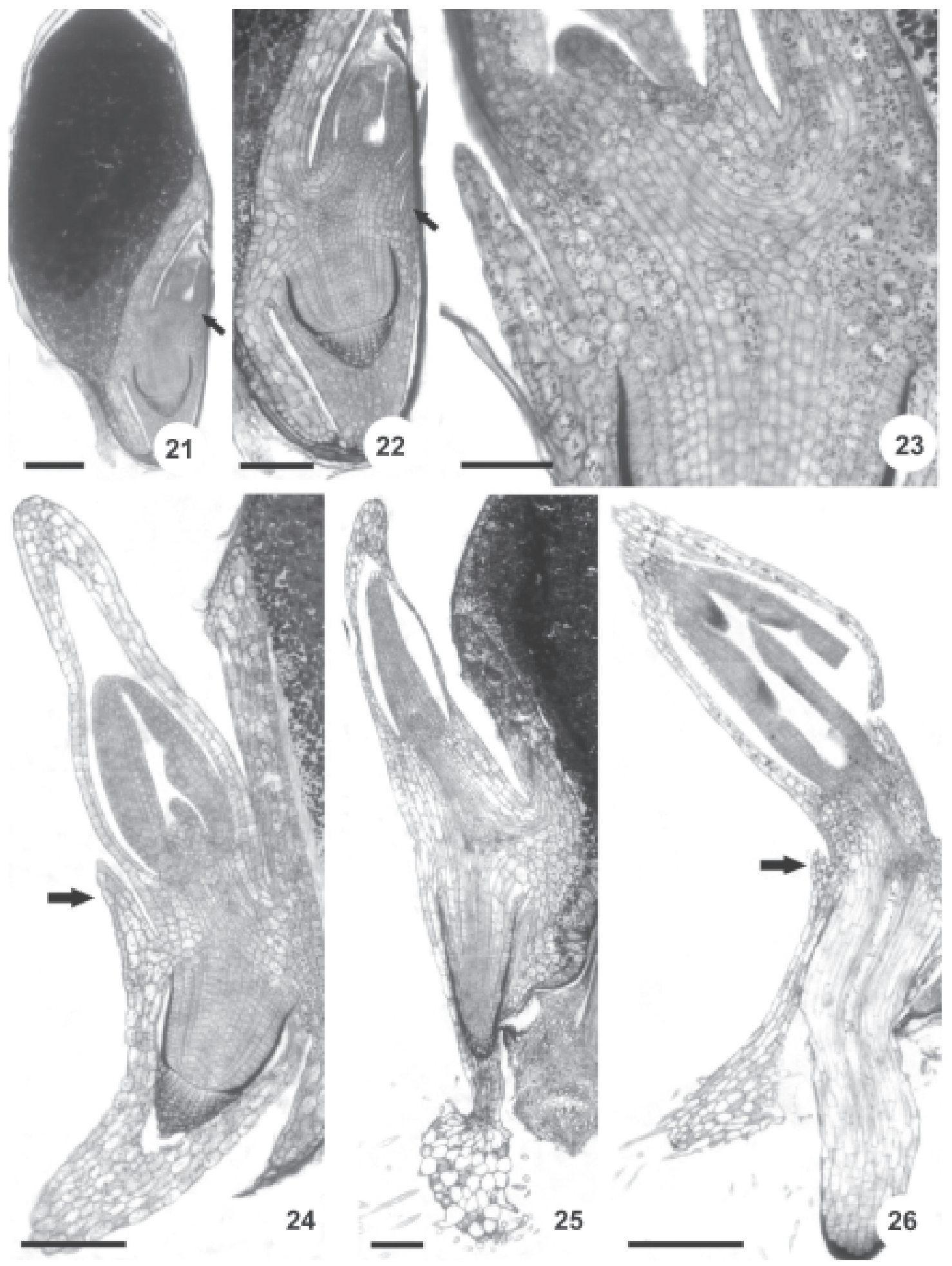

Figuras 21-26. Fotomicrografias do desenvolvimento pós-seminal de espécies de Poaceae em secção longitudinal. 21-24, 26. Chloris elata Nees (Chloridoideae). 25. Axonopus aureus P. Beauv. (Panicoideae). 21. Cariopse com 4 horas de embebição. 22. Detalhe do embrião. 23. Detalhe do embrião, evidenciando os tecidos meristemáticos. 24. Início da germinação, plântula com 16 horas após início da embebição. 25. Plântula de 24 horas. 26. Plântula de 36 horas. Seta = epiblasto. Barras = $400 \mu \mathrm{m}(22,25) ; 200 \mu \mathrm{m}(23) ; 150 \mu \mathrm{m}(21,24,26)$. 


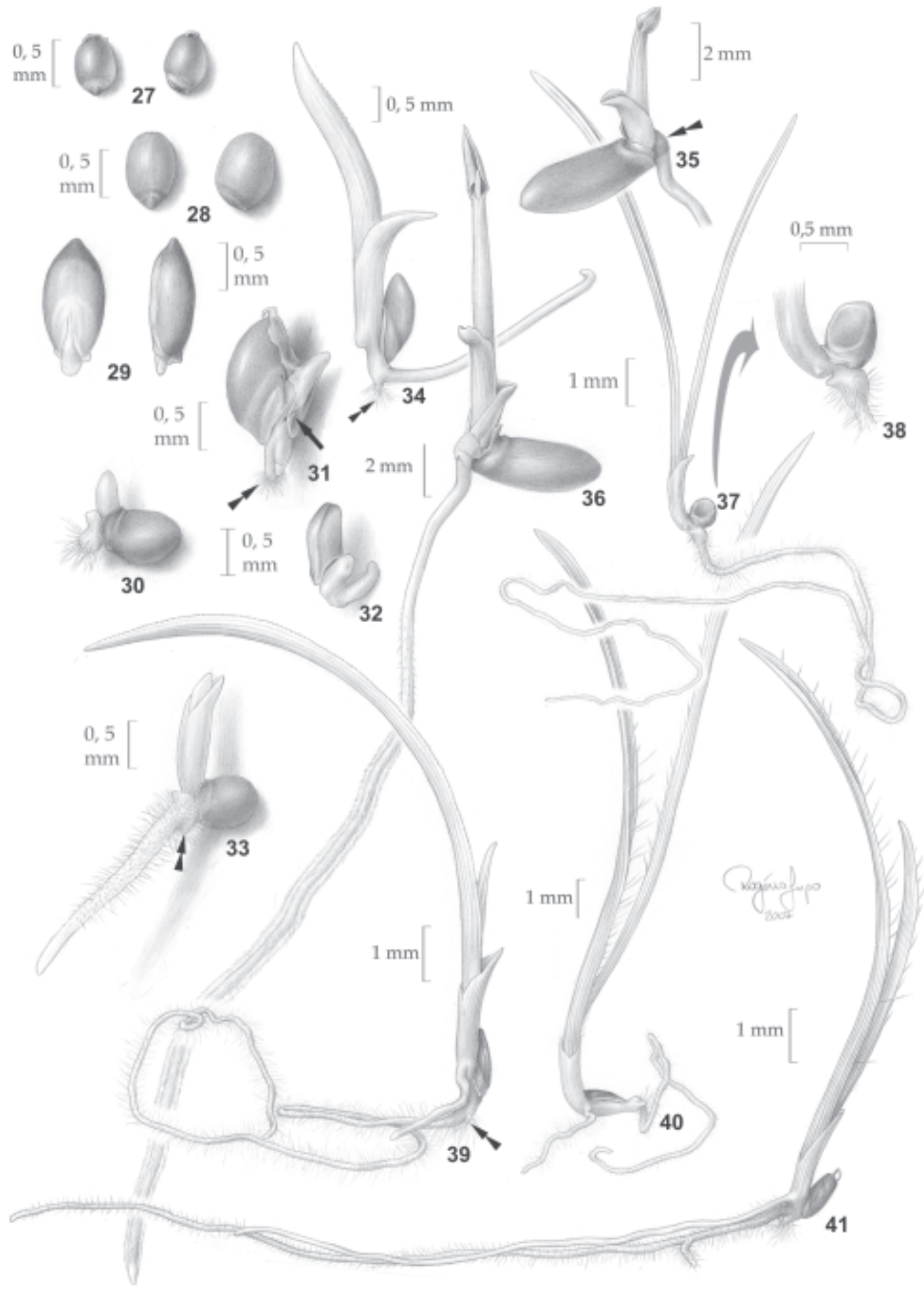

Figuras 27-41. Morfologia do desenvolvimento pós-seminal de espécies de Poaceae. As horas são contadas a partir do início da embebição. 27-28. Vista frontal e lateral do fruto de Eragrostis solida Desv. (Chloridoideae) - seco e embebido, respectivamente. 29. Vista frontal e lateral do fruto de Axonopus aureus P. Beauv. (Panicoideae) - emissão da coleorriza (24 horas). 30. Eragrostis solida Desv. (Chloridoideae), emissão do coleóptilo - 24 horas. 31. Chloris elata Nees (Chloridoideae), raiz endógena (adventícia) rompe a coleorriza - 24 horas. 32. Paspalum polyphyllum Nees ex Trin. (Panicoideae) - 24 horas. 33. Eragrostis solida Desv. (Chloridoideae), primeiras folhas em desenvolvimento - 48 horas. 34. Chloris elata Nees (Chloridoideae) - 48 horas. 35. Olyra humilis Nees (Bambusoideae) - 8 semanas e 72 horas. 36. Olyra humilis Nees (Bambusoideae) - 8 semanas e 144 horas. 37, 38. Eragrostis solida Desv. (Chloridoideae), vista geral e detalhe do início do desenvolvimento da raiz adventícia - 96 horas. 39. Chloris elata Nees (Chloridoideae) - 96 horas. 40. Axonopus aureus P. Beauv. (Panicoideae) - 96 horas. 41. Paspalum polyphyllum Nees ex Trin. (Panicoideae) - 120 horas. Dupla ponta de seta = pólo radicular; Seta = epiblasto. 
que escutelo é homólogo à lâmina foliar, coleóptilo é homólogo à lígula e epiblasto é homólogo à bainha.

No estudo, acredita-se que o cotilédone das espécies estudadas pode ser dividido em três regiões: escutelo, também denominado de hiperfilo ou haustro (Tillich 1995; 2000; 2007) que é a porção distal do cotilédone e apresenta função de absorção de nutrientes do endosperma (Tillich 2000; 2007); bainha reduzida; e coleóptilo, que é a porção inferior do cotilédone, também denominado de hipofilo (Tillich 2007).

A divisão do cotilédone em partes é consenso para diversos autores (Sargant \& Arber 1915; Cocucci \& Astegiano 1978; Shuma \& Raju 1991; Tillich 1995; 2000; 2007), porém sua homologia ainda é discutida. Shuma \& Raju (1991) consideraram o escutelo e o coleóptilo como partes de um órgão foliar simples, homólogo ao cotilédone. Para esses autores o escutelo representa a parte basal da folha e o coleóptilo equivale à lâmina reduzida, devido à presença de traços vasculares, estômatos e cloroplatos. Sargant \& Arber (1915) apontaram em Avena que o escutelo é homólogo ao haustro e o coleóptilo homólogo à bainha do cotilédone, como foi relatado posteriormente por Tillich (1995; 2000).

Considerando as atuais 17 famílias de Poales (APG II 2003) com exclusão de Hydatellaceae, grupo irmão de Nympheales (Saarela et al. 2007), o coleóptilo está presente em Cyperaceae (Walters 1950), Joinvilleaceae (Tillich 2007), algumas espécies de Restionaceae (Linder \& Caddick 2001) e Poaceae (Walters 1950). Provavelmente para Poaceae e Cyperaceae este caráter pode ser considerado convergência morfológica. Entre os representantes do clado "graminídeo" proposto por Linder \& Rudall (2005), o coleóptilo está presente em Poaceae (GPWG 2001) e Joinvilleaceae (Tillich 2007). Se estiver presente em representantes de Ecdeiocoleaceae, coleóptilo pode ser um caráter importante compartilhado entre os representantes desse clado, apesar de estar ausente em Flagellariaceae (Tillich 1996). Em Restionaceae o coleóptilo pode ser considerado uma reversão (Tillich 2007). Dentre as monocotiledôneas, coleóptilo é um caráter que ocorre em diversos representantes e evoluiu inúmeras vezes (Tillich 1995).

Internamente ao coleóptilo, observa-se a plúmula com primórdios foliares e meristema apical caulinar. A primeira folha plumular que se desenvolve na plântula das monocotiledôneas apresenta importância para a sistemática (Tillich 2000). No presente estudo, foi observado que somente em Olyra humilis (Bambusoideae) a primeira folha apresentou características de catafilo, com bainha alongada e limbo foliar reduzido. Catafilos também foram encontrados em espécies de Zingiberaceae (Boyd 1932), Heliconiaceae (Simão \& Scatena 2003) e em Cannaceae (Boyd 1932), e pode ser considerado um caráter ancestral (Tillich 2000). Olyra humilis é considerada basal em relação às demais espécies estudadas, e a presença de catafilo como primeira folha em suas plântulas, confirma sua posição basal em relação à Axonopus aureus, Paspalum polyphyllum (Panicoideae), Chloris elata e Eragrostis solida (Chloridoideae).

O epiblasto, aqui descrito como folha embrionária, inicialmente havia sido interpretado como excrescência lateral da coleorriza, devido à ausência de vascularização. Em embrião de trigo Foard \& Haber (1962) consideraram epiblasto e coleorriza como estruturas contínuas. Em Oryzopsis miliaceae, Negbi \& Koller (1962) discordaram e mostraram evidências de que epiblasto, escutelo e coleóptilo são as três primeiras folhas embrionárias.

Estudos de desenvolvimento do embrião de trigo in vitro evidenciaram que epiblasto e escutelo podem formar um tecido capaz de regenerar plantas inteiras, mas coleorriza não (Ozias-Akins \& Vasil 1983). Estes autores verificaram a origem cotiledonar do epiblasto, que pode ser considerado parte de uma folha embrionária, descartando-se a possibilidade de epiblasto ser uma excrescência da coleorriza (Tillich 1995; 2000) ou forma reduzida do colar (Dahlgren et al. 1985).

Epiblasto é uma estrutura embrionária que ocorre em táxons basais de Poaceae e também em Chloris elata e Eragrostis solida (Chloridoideae), bem como na maioria dos representantes desta subfamília, (GPWG 2001). É exclusivo dos embriões de Poaceae e, portanto, não é homólogo a nenhuma outra estrutura de outras monocotiledôneas (GPWG 2001).

A coleorriza nas espécies estudadas apresenta-se parenquimática, não vascularizada, com epiderme tricomatosa. Acredita-se que ela representa a redução da raiz primária, corroborando com dados de Cocucci \& Astegiano (1978) e Dahlgren et al. (1985). Nas sementes de Angiospermas em geral, observa-se que o suspensor está sempre ligado à radícula, e em Poaceae, está ligado à coleorriza. Nas espécies de Poaceae estudadas, a raiz primária é suprimida, pois cessa seu crescimento pouco depois da protrusão (germinação) e permanece na plântula apenas como resquício, indicando o pólo radicular. $\mathrm{O}$ processo de supressão da raiz primária de plântulas de monocotiledôneas culmina com sua ausência (Boyd 1931), como último passo evolutivo da raiz primária de plântulas de monocotiledôneas (Tillich 2000; 2007).

Para monocotiledôneas, Tillich (1995) sugeriu que a presença de raiz primária é, provavelmente, condição ancestral para o grupo. Para Poales, sua presença foi observada na maioria das famílias, destacando-se sua redução ou ausência em algumas famílias. Em 
Bromeliaceae, família considerada basal dentro de Poales (APG II 2003), foi observada presença e ausência de raiz primária. Pereira (1988) observou a presença de raiz primária vigorosa em plântulas de Bromelioideae. Tillich (1995) e Scatena et al. (2006) não observaram a raiz primária em Tillandsioideae. Ramaswamy et al. (1981), Scatena et al. $(1993 ;$ 1996) e Tillich $(1995 ; 2007)$ relataram ausência de raiz primária em plântulas de Eriocaulaceae. Tillich (2007) observou a ausência de raiz primária em Mayacaceae (Mayaca fluviatilis).

Em Poaceae, a redução da raiz primária é um caráter derivado, como relatado por Boyd (1932) e Tillich (1995), assim como nos demais representantes de Poales (Tillich 2007). Nas monocotiledôneas, em geral, a ausência de raiz primária nas plântulas é um caráter derivado, que ocorre com certa freqüência durante a evolução, seguindo linhas filogenéticas distintas (Tillich 1995).

Os resultados desse estudo demonstraram que as espécies apresentam o início do desenvolvimento pósseminal semelhante, observando-se inicialmente a protrusão da coleorriza, seguida do coleóptilo e plúmula, e pode ser considerado um padrão para Poaceae. Entretanto, o desenvolvimento da primeira folha plumular mostrou uma diferença em Olyra humilis (Bambusoideae), única espécie a apresentar catafilo, característica que sugere a ancestralidade dessa espécie em relação às demais aqui estudadas.

\section{Agradecimentos}

Ao Conselho Nacional de Desenvolvimento e Pesquisa $(\mathrm{CNPq})$, pela bolsa de doutorado concedida à primeira autora (proc. 140022/2004-0) e bolsa de produtividade à segunda autora (proc. 301404/2004-6). Auxílios financeiros CNPq (proc. 471809/2004-7) e Fundação de Amparo à Pesquisa do Estado de São Paulo (FAPESP) (proc. 2005/02141-4). À Dra. Hilda M. Longhi-Wagner, pelo auxílio na revisão do texto, identificação botânica e imagens cedidas (Fig. 1, 3, 5, 7, 10).

\section{Referências bibliográficas}

Angiosperm Phylogeny Group (APG II). 2003. An update of the Angiosperm Phylogeny Group classification for the order and families of flowering plants: APG II. Botanical Journal of the Linnean Society 141: 399-436.

Boechat, S.C.; Guglieri, A. \& Longhi-Wagner, H.M. 2001. Tribo Eragrostideae. Pp. 61-84. In: M.G.L. Wanderley, G.J. Shepherd, A.M. Giulietti (eds.). Flora Fanerogâmica do Estado de São Paulo. v.1. Poaceae. São Paulo, HUCITEC.

Boyd, L. 1931. Evolution in the monocotyledonous seedling: a new interpretation of the morphology of the grass embryo. Transaction and Proceedings/Botanical Society of Edinburgh 30: 286-303.
Boyd, L. 1932. Monocotylous seedling: morphological studies in the post-seminal development of the embryo. Transaction and Proceedings/Botanical Society of Edinburgh 31: 1-224.

Cocucci, A.E. \& Astegiano, M.E. 1978. Interpretacion del embrion de las Poáceas. Kurtziana 11: 41-54.

Dalhgren, R.M.T.; Clifford, H.T. \& Yeo, P.F. 1985. The families of the monocotyledons: structure, evolution and taxonomy. Berlin, Springer-Verlag.

Eames, A.J. 1974. Morphology of the angiosperms. New Delhi, Tata McGraw-Hill.

Feder, N. \& O'Brien, T.P. (1968). Plant microthecnique: some principles and new methods. American Journal of Botany 55: 123-142.

Foard, D.E. \& Haber, A.H. 1962. Use of growth characteristics in studies of morphology relations. I. Similarities between epiblasto and coleorhiza. American Journal of Botany 49: 520-523.

Grass Phylogeny Working Group (GPWG). 2001. Phylogeny and subfamilial classification of grasses (Poaceae). Annals of the Missouri Botanical Garden 88: 373-457.

Gunn, C.R. 1981. Seeds of Leguminosae. Pp. 913-925. In: R.M. Polhill \& P.H. Raven (eds.). Advances in legume systematics. Kew, Crow copyright.

Johansen, D.A. 1940. Plant microtechnique. New York, McGraw-Hill Book.

Linder, H.P. \& Caddick, L. 2001. Restionaceae seedlings: morphology, anatomy, and systematic implications. Feddes Repertorium 112: 59-80.

Linder, H.P. \& Rudall, P.J. 2005. Evolutionary history of Poales. Annual Review of Ecology, Evolution and Systematics 36: $107-124$.

Longhi-Wagner, H.M. 2001. Tribo Cynodonteae (Chlorideae). Pp. 49-61. In: M.G.L. Wanderley, G.J. Shepherd, A.M. Giulietti (eds.). Flora Fanerogâmica do Estado de São Paulo. v.1. Poaceae. São Paulo, HUCITEC.

Martin, A.C. 1946. The comparative internal morphology of seeds. The American Midland Naturalist 36: 513-660.

Negbi, M. \& Koller, D. 1962. Homologies in the grass embryo - a re-evaluation. Phytomorphology 12: 289-296.

Oliveira, R.C. \& Valls, J.F.M. 2001. Paspalum P. Pp. 191-228. In: M.G.L. Wanderley; G.J. Shepherd \& A.M. Giulietti (eds.). Flora Fanerogâmica do Estado de São Paulo. v.1. Poaceae. São Paulo, HUCITEC.

Oliveira, R.P. \& Longhi-Wagner, H.M. 2001. Olyra L. Pp. 45-47. In: M.G.L. Wanderley; G.J. Shepherd \& A.M. Giulietti (eds.). Flora Fanerogâmica do Estado de São Paulo. v.1. Poaceae. São Paulo, HUCITEC.

Ozias-Akins, P. \& Vasil, I.K. 1983. Proliferation of and plant regeneration from the epiblast of Triticum aestivum (wheat; Gramineae) embryos. American Journal of Botany 7: 1092-1097.

Pereira, T.S. 1988. Bromelioideae (Bromeliaceae) Morfologia de desenvolvimento pós-seminal de algumas espécies. Arquivos do Jardim Botânico do Rio de Janeiro 29: 115-154.

Reeder, J.R. 1957. The embryo in grass systematics. American Journal of Botany 44: 756-768.

Reeder, J.R. 1962. The bambusoid embryo: a reappraisal. American Journal of Botany 49: 639-641. 
Ramaswamy, S.N.; Swamy, B.G.L. \& Arekal, G.D. 1981. From zygote to seedling in Eriocaulon robusto-brownianum Ruhl. (Eriocaulaceae). Beitrage zur Biologie der Pflanzen 55: 179-188.

Roth, I. 1987. A stratification of a tropical forest as seen in dispersal types. Dordrecht-Boston-Lancaster, Junk Publ.

Saarela, J.M.; Rai, H.S.; Doyle, J.A.; Endress, P.K.; Mathews, S.; Marchant, A.D.; Briggs, B.G. \& Graham, S.W. 2007. Hydatellaceae identified as a new branch near the base of the Angiosperm phylogenetic tree. Nature 446: 312-315.

Sargant, E. \& Arber, A. 1915. The comparative morphology of the embryo and seedling in the Gramineae. Annals of Botany 29: $161-222$.

Scatena, V.L.; Lemos Filho, J.P. \& Lima, A.A.A. 1996. Morfologia do desenvolvimento pós-seminal de Syngonanthus elegans e $S$. niveus (Eriocaulaceae). Acta Botanica Brasilica 10: 85-91.

Scatena, V.L.; Menezes, N.L. \& Stützel, T. 1993. Embryology and seedling development in Syngonanthus rufipes Silveira (Eriocaulaceae). Beitrage zur Biologie der Pflanzen 67: 333-343.

Scatena, V.L.; Segecin, S. \& Coan, A.I. 2006. Seed morphology and post-seminal development os Tillandsia L. (Bromeliaceae) from the "Campos Gerais", Paraná, Southern Brazil. Brazilian Archives of Biology and Technology 49: 945-951.
Shuma, J.M. \& Raju, M.V.S. 1991. Is the wild oat embryo monocotylous? Botanical Magazine Tokyo 104: 15-23.

Simão, D.G. \& Scatena, V.L. 2003. Morphological aspects of the propagation in Heliconia velloziana L. Emygd. (Zingiberales: Heliconiaceae). Brazilian Archives of Biology and Technology 46: 65-72.

Tillich, H.-J. 1995. Seedlings and systematics in monocotyledons. Pp. 303-352. In: P.J. Rudall; P.J. Cribb; D.F. Cutler \& C.J. Humphries (eds.). Monocotyledons: systematics and evolution. Kew, Royal Botanic Gardens.

Tillich, H.-J. 1996. Seeds and seedlings in Hanguanaceae and Flagellariaceae (Monocotyledons). Sendtnera 3: 187-197.

Tillich, H.-J. 2000. Ancestral and derived caracter states in seedlings of monocotyledons. Pp. 221-228. In: K.L. Wilson \& D.A. Morrison (eds.). Monocots: Systematics and evolution. Melbourne, CSIRO.

Tillich, H.-J. 2007. Seedling diversity and homologies of seedling organs in the order Poales (Monocotyledons). Annals of Botany 100: 1-17.

Valls, J.F.M.; Longhi-Wagner, H.M. \& Boldrini, I.I. 2001. Axonopus P. Beauv. Pp. 129-141. In: M.G.L. Wanderley; G.J. Shepherd \& A.M. Giulietti (eds.). Flora Fanerogâmica do Estado de São Paulo. v.1. Poaceae. São Paulo, HUCITEC.

Walters, S.M. 1950. On the Vegetative Morphology of Eleocharis R. Br. New Phytologist 49: 1-7.

Werker, E. 1997. Seed anatomy. Berlin, Gebrüder Borntraeger. 